\title{
ANÁLISE DO ELEMENTO LOGÍSTICA (PRAÇA) NO SETOR DE EVENTOS
}

\author{
Fábio Luciano Violin, Renata Maria Ribeiro \\ Universidade Estadual Paulista “úlio de Mesquita Filho” - UNESP. Curso de Turismo. E-mail: violin@rosana.unesp.br
}

\section{RESUMO}

O Composto de Logística é apresentado como o foco central desse estudo no contexto de análise em vinte e cinco empresas de eventos. Todas participaram de um processo de concorrência a um prêmio de amplitude nacional. A escolha desse público alvo foi feita por se julgar que a seleção ao prêmio foi a partir de critérios de qualidade às empresas aptas a concorrer. Através da revisão da literatura, análise de dados primários e secundários bem como o alinhamento de um instrumento adequado de averiguação da realidade, foi possível apontar os principais elementos do composto de logística utilizados pelas organizações, emergindo desse levantamento a percepção de elevado grau de proficiência dentro do contexto logístico por parte das organizações; mesmo sem a apresentação de qualificação técnica comprovada.

Palavras - chave: Turismo; Composto de Marketing, Logística, Eventos, Percepção.

\section{ANALYSIS OF PLACE ELEMENT IN SECTOR EVENTS}

\begin{abstract}
Compound Logistics is presented as the central focus of this study in the context of analysis in twenty-five companies of events. All participated in a competitive process to an extensive national award. The choice of this target audience was made by judging that the selection for the award was based on criteria of quality to companies able to compete. Through literature review, analysis of primary and secondary data as well as the alignment of a suitable tool of investigation of reality, it was possible to identify the main elements of the compound used by logistics organizations, emerging from this survey perceived high degree of proficiency in context of logistics organizations; even without the presentation of proven technical expertise.
\end{abstract}

Keywords: Tourism; Marketing Mix, Distribution, Events, Perception. 


\section{INTRODUÇÃO}

A proficiência no contexto logístico nas organizações de modo geral apresenta uma carga extra de dificuldade em sua execução considerando que suas ações extrapolam a simples execução de atividades fim. O elemento estratégico está presente em todos os momentos e envolve os demais elementos do Composto de Marketing (produtos, preço e comunicação) ao contemplar formas de disponilizar onde, como, quando, de que forma e em quais condições um produto ou serviço deve ser disponibilizado a quem o consumirá.

O contexto de competitividade aliada a mudanças estruturais rápidas e constantes faz emergir nas organizações a necessidade de se atingir objetivos de curto, médio e longo prazo, tornando vital a montagem de estratégias refinadas para a prospecção, captação e manutenção de uma carteira de clientes (turistas ou usuários) que permita a obtenção de resultados almejados dentro de um determinado período.

A tarefa de obter e manter resultados positivos traz em seu cerne a dificuldade de resultados permanentes visto que as organizações são criações humanas desprovidas de permanência efetiva e real, cuja função maior é a de servir a seus objetivos aliados a sua contribuição para com a sociedade e a economia de um país, região ou local específico. A perpetuação de uma organização segundo Drucker (2002), é tarefa básica que cabe ao espírito empreendedor e atingir tal intento é o teste definitivo da capacidade de administração de seus gestores.

Para Andrade e Santos (2004) o reflexo imediato do desenvolvimento do segmento de turismo de eventos tem se configurado na dotação de infraestruturas receptivas e promocionais cada vez maiores nas cidades. Os eventos podem ocorrer durante todo o ano, minimizando assim, alguns efeitos negativos sobre alguns empreendimentos turísticos, principalmente a rede hoteleira.

As ações de Marketing visam em essência proporcionar satisfação na relação entre uma organização e seus clientes, sejam eles reais ou potenciais. Ao considerar as taxas de mortalidade de empresas em especial as iniciantes, pode-se inferir a necessidade de conhecimento sistematizado a respeito do mercado e os elementos do composto podem ser auxiliares nesse processo de definição das ações a serem tomadas considerando os objetivos a serem atingidos. (VIOLIN et. al, 2013a).

As ações mercadológicas são apontadas como capazes de agregar valor a produtos e serviços com foco na atração, estímulo e gestão da demanda tendo como base a identificação de necessidades e desejos dos consumidores dentro dos segmentos de mercado. As organizações 
ofertam produtos como bens físicos, serviços, ideias, lugares, pessoas ou informações para atender as demandas específicas, podendo ser considerado um produto de qualquer oferta que venha ao encontro de uma necessidade ou desejo (KOTLER, 2009).

Originalmente esse elemento foi traduzido no Brasil como Praça contudo, os conceitos associados a ideia de distribuição e mais modernamente logística ganharam espaço ao contemplarem as ações pertinentes a todo processo desde a concepção do produto ou serviços até sua disponibilziação para uso dos consumidores.

As estratégias de distribuição relacionam-se aos canais utilizados dentro do mercado o qual representa segundo Ferrell et. al. (2000, p. 98) um "[...] sistema de organizações pelo qual um produto, recursos, informações e/ ou propriedades flui de produtores a consumidores" e ainda segundo os mesmos autores esse conceito se estende as ações vinculadas à distribuição física a qual foi conceituada como toda a "[...] movimentação de produtos ao local adequado, nas quantidades e no tempo corretos, de maneira eficiente em termos de custo".

Salienta-se que as atividades de distribuição encerram as questões vinculadas por exemplo a estocagem movimentação de matérias-primas e materiais, tipos e formas de transporte, organização e uso de equipamentos entre diversos outras ações ou instrumentalizações associadas que sejam necessárias para o correto fluxo de trocas entre os "produtores" e os usuários de produtos, serviços, ideias entre outros.

Segundo Churchill e Peter (2005), o canal de distribuição representa uma rede (ou sistema) organizado de órgãos e instituições que executam todas as funções necessárias para ligar os produtores aos usuários finais.

As estratégias vinculadas ao composto de distribuição analisadas nesse estudo são as seguintes:

Canais: representa o caminho percorrido pelo produto na transferência de quem o produz até quem o consome podendo ser direto ou indireto. Os canais podem ser físicos ou virtuais e incluem atacadistas, varejistas, representantes diretos, vendas diretas ou ainda a conjunção de mais de um ou vários elementos constituintes do canal (KOTLER e ARMSTRONG, 2007).

Cobertura: representa o espaço geográfico coberto pela organização, valendo-se modernamente do conceito de cobertura mundial ou nacional proporcionado pelos meios virtuais (FERRELL et.al, 2000).

Variedade: refere-se ao conjunto de diferentes possibilidades pelos quais os produtos ou serviços de uma organização podem ser combinados (CHURCHILL e PETER, 2005).

Locais: referem-se ao (s) ponto (s) de distribuição que a organização disponibiliza, bem 
como a natureza desses locais como forma de analisar de modo correto o tipo, a quantidade e a adequação do que está sendo ofertado ao mercado (KOTLER e KELLER, 2006).

Transporte: refere-se aos meios pelos quais os produtos serão deslocados. O uso de um ou mais tipos de transportes variam conforme a localização geográfica, natureza do bem entre outros elementos. Os meios mais comuns são os transportes rodoviários, ferroviários, aéreos e viários (LAS CASAS, 2007).

Esse elemento do composto é especialmente importante pois, figura como um importante centro tanto de custos quando de percepção positiva ou negativa dos consumidores. Falhas no campo da distribuição ou logística costumam gerar resultados negativos de monta relevante tanto financeira quanto em termos de imagem.

Dessa forma o presente estudo se propôs a levantar e apresentar as principais valorações atribuídas pelas organizações do setor de eventos em relação ao uso das ferramentas vinculadas aos compostos praça (logística).

\section{METODOLOGIA}

Levantar dados considerando as peculiaridades de boa parte das empresas nacionais não é trabalho fácil e de rápido retorno. Nesse sentido esse material faz parte de um conjunto de dados obtidos junto a empresas vinculadas ao setor de eventos em um esforço inicial para trazer à tona sua lógica de tomada de decisão pautada no plano estratégico de cada organização no que concerne especificamente ao composto mercadológico e suas vinculações e nesse caso especificamente o elemento logística.

Considerando esses apontamentos observa-se a pesquisa exploratória é a tônica do estudo e sobre a qual Gil (2008), defende que a mesma pode gerar maior familiaridade com o problema ao buscar elementos para explicitá-los. Tal prerrogativa é atendida pelo estudo que buscou obter o aceite de participação de cinco empresas de cada um dos seguintes ramos: Captação de eventos; Organização de congresso; Convenções (sob demanda); Viagens de Incentivo e Seminários e fóruns (sob demanda).

Como recorte temporal aponta-se que os levantamentos de dados se deu entre Abril e Junho de 2014 e compreendeu o contato com empresas privadas do setor de eventos que concorreram figuraram entre os anos de 2007 a 2013 na lista das selecionadas para concorrerem a um prêmio de amplitude nacional vinculado ao setor.

Tal opção configura então uma amostra por julgamento a qual segundo Churchill (1998) tem como característica chave na seleção de elementos da população a intencionalidade 
considerando que a mesma poderá oferecer contribuições dentro do contexto almejado.

Os dados foram obtidos através da análise do plano estratégico efetivamente realizado no período em que cada organização concorreu ao prêmio e sua disponibilização para análise dos dados se deu através da inserção em questionário online restrito de fragmentos advindos do referido plano estratégico.

Esta pesquisa faz parte de um estudo maior que envolve os demais elementos do Composto de Marketing. Contudo, por uma questão de espaço e regramento não é possível inserir todos os dados em um único material, optando-se assim por fragmentar a apresentação da revisão teórica e dos dados obtidos em campo e apresentar cada parte de modo isolado já que cada elemento foi tratado no estudo maior de modo compartimentado.

\section{RESULTADOS}

As empresas participantes responderam em cada uma das dimensões propostas qual seu grau de proficiência no trato com cada elemento pertencente ao Composto de Produto sendo o primeiro questionamento o seguinte: Qual o grau de proficiência da organização em relação a cada um dos elementos do Composto de Logística e as respostas foram as seguintes:

Quadro 1. Utilização de Ferramentas do Composto Logístico

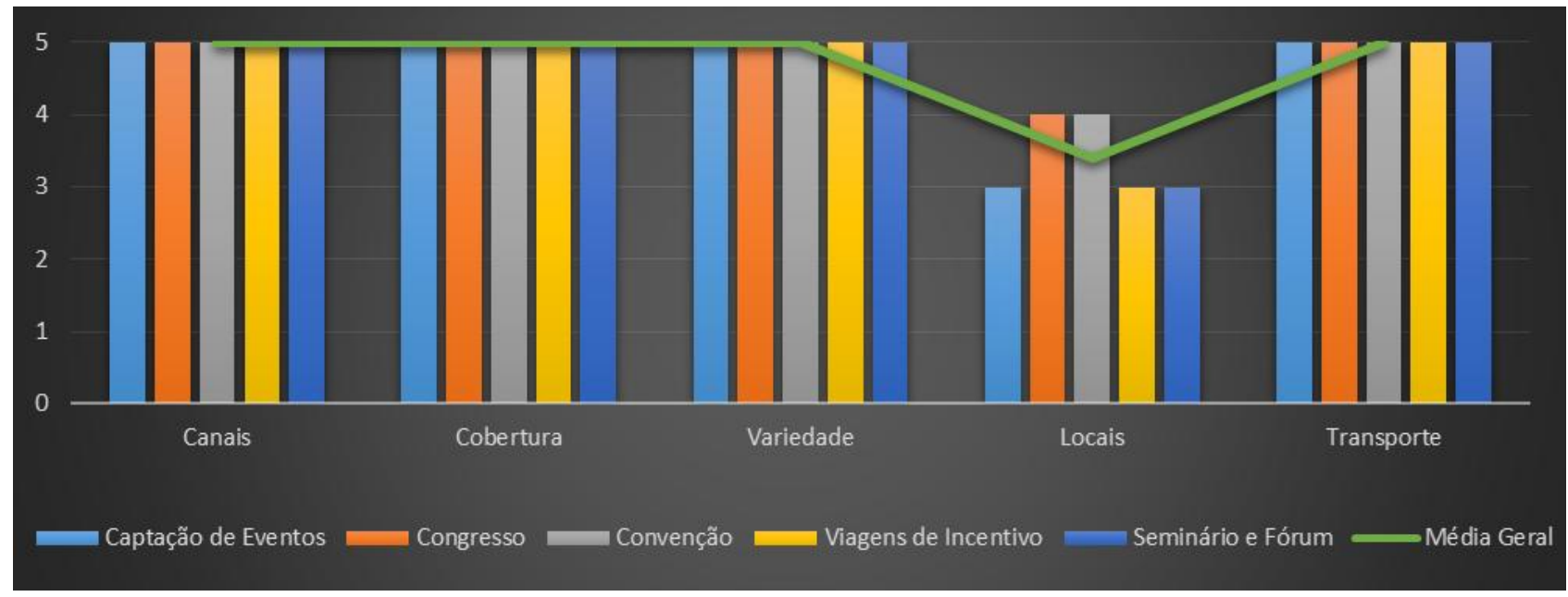

Fonte: autores

Os dados apresentam-se contundentes e serão tratados na discussão dos mesmos contudo, aponta-se para a importância atribuída pelo conjunto das empresas pesquisadas em relação ao poder estratégico desse elemento do composto com destaque para a declaração de 96\% deles que apontaram esse composto como o mais difícil de ser trabalho e o que pode isoladamente gerar maiores danos segundo $92 \%$ das empresas. 


\section{DISCUSSÃO}

Nenhum outro elemento do composto de Marketing estudados anteriormente apresentou tantos itens de confluência e concordância quanto a sua importância observada pela harmonia da linha que representa a média geral em cada item.

A proficiência logística segundo $96 \%$ do público alvo é vital para a execução das atividades, segundo eles erros aqui costumam gerar transtornos de monta elevada e com difícil possibilidade de adequação em curto espaço de tempo.

Destaca-se que a terceirização foi apontada por Violin et. al (2013c) como elemento fortemente presente na constituição das estratégias em organizações de eventos e no item logística dentro do grupo pesquisado essa tendência se confirmou ao obter-se a informação de que todas as organizações pesquisadas possuem serviços terceirizados ao longo de sua cadeia de "produção" e o elemento logístico apresenta-se como estratégico e vital nesse contexto, porém, $88 \%$ do público alvo apontou a necessidade de estabelecimento de padrões rígidos em termos de prazos, padrão de conduta, condições de execução entre outros itens que apontam a emergência de profissionalismo na parceria.

A importância da aliança entre e harmonia entre os itens que compõem o composto de Logística foi apontado por $96 \%$ das empresas como vitais para a organização das ações da empresa e $100 \%$ das empresas destacaram que falhas na formulação logística e sua harmonização com os demais elementos do composto representam alta probabilidade de prejuízos se mal administrado, apontamento corroborado por Violin et. al (2013b) que destaca que o composto de Marketing é um dos pilares vinculados ao sucesso ou fracasso de novos produtos no mercado.

Ponto pacífico para $92 \%$ das empresas que esse elemento do composto é um dos mais difíceis de ser dimensionado e gerido do ponto de vista operacional considerando as decisões futuras que decorrem da análise do equilíbrio ideal entre os itens que compõem esse grupo de decisões estratégicas.

\section{CONCLUSÃO}

As entrevistas realizadas com as organizações apontaram para a existência de forte relação entre as estratégias mercadológicas e o ambiente em que operam as organizações. Quando se observa que $92 \%$ das empresas destaca a necessidade constante de análise ambiental reforçando a premência de um composto afinado com as mutantes necessidades ou exigências de mercado enceta-se que o direcionamento estratégico encerra em si ponto pacífico de atuação com vistas a permanência ou projeção mercadológica das organizações. 
Esse apontamento encontra eco em Violin et. al (2013c) o qual aponta para a existência de certo equilíbrio dinâmico advindo da percepção das empresas no sentido de apesar de serem organizações diferentes a validação das ferramentas mercadológicas apresenta de similaridade em termos de uso e figuração de relevância nas definições estratégicas.

O Composto Logístico segundo 96\% das empresas inspira cuidados pela dificuldade técnica de execução, o que levou esse item a ser considerado o mais importante por $28 \%$ das empresas. Novamente, o item recebe corroboração de importância em Violin et. al (2013a) que destaca os movimentos em relação a terceirização e Violin (2013c) que aponta a Logística como um dos elementos vitais para as considerações quando da execução do planejamento estratégico organizacional.

A terceirização no setor de eventos traz o elemento logístico como um dos itens que mais recebe mão de obra segundo $96 \%$ das empresas, esse dado conduz a sugestão de cuidados que inspiram esse elemento do composto de Marketing pois, erros nesse quesito por sua dimensão tem o poder de impactar de modo substancial os resultados, especialmente os negativos.

\section{REFERÊNCIAS}

ANDRADE, J. R. de L. e SANTOS, C. A. de J. Eventos e Estratégia de Desenvolvimento Turístico. O caso de Aracajú. Revista Bibliográfica de Geografía y Ciencias Sociales. (Serie documental de Geo Crítica). Universidad de Barcelona. Vol. IX, no 543, 30 de octubre de 2004.

CHURCHILL, G. A. Jr., PETER, J. P. Marketing: criando valor para os clientes. São Paulo: Saraiva, 2005.

CHURCHILL, Gilbert. Marketing Research: Methodological Foundations. 2 ed. The Dryden Press. 1998.

DRUCKER, P. F. Introdução à Administração. São Paulo: Pioneira Thomson; 2002.

FERRELL, O.C.; HARTLINE, Michael D. Estratégia de Marketing. São Paulo: Pioneira Thomson Learning, 2005.

GIL, A. C. Como Elaborar Projetos de Pesquisa. 4o ed. São Paulo: Atlas, 2008.

KOTLER, P.Marketing para o século XXI: como criar, conquistar e dominar mercados. SãoPaulo: Ediouro, 2009.

e KELLER, Kevin Lane. Administração de Marketing: A Bíblia do Marketing. 12ㅇed.

Prentice Hall Brasil, 2006.

.; ARMSTRONG, G. Princípios de Marketing. 12. ed. São Paulo: Prentice Hall, 2007.

LAS CASAS; Alexandre L. Marketing de serviços. 5. ed. São Paulo: Atlas, 2007. 
SELTIZ, C.; WRIGHTSMAN, L.S.; COOK, S.W. Métodos de pesquisa nas relações sociais. 2o ed. São Paulo: EPU, 1987.

VIOLIN, Fábio Luciano Violin; VIOLIN, André Luiz e VIOLIN, Patrícia Koerich Violin. Estratégias Competitivas e o Insucesso de Novos Produtos. ADMPG - Congresso Internacional de Administração. $s / n, 2013 b$.

.Aporte das Estratégias Mercadológicas na Promoção de Eventos em Organizações Premiadas com o prêmio Caio.VIII Congresso Brasileiro de Turismo Rural e I Colóquio Internacional de Pesquisa e Práticas em Turismo Rural. s/n, 2013c.

Letícia Borges e SILVA, Graziela. Levantamento das Estratégias do Composto de Marketing praticadas por empresas vinculadas ao Turismo: Estudo Multicaso. VIII Congresso Brasileiro de Turismo Rural e I Colóquio Internacional de Pesquisa e Práticas em Turismo Rural, p. $249-254,2013$ a.

YUDELSON, J. Adapting McCarthy's Four P's for the Twenty-First Century. In: Journal of Marketing Education, vol. 21, no 1, p.60-67, abr. 1999. http://dx.doi.org/10.1177/0273475399211008 